\title{
BENEFACTIVE VERBS AND CAUSATIVE VERBS IN MADURESE: MORPHOSYNTACTIC ANALYSIS
}

\author{
Farda Naila Salsabila ${ }^{1}$ \\ Universitas Diponegoro \\ Agus Subiyanto ${ }^{2}$ \\ Universitas Diponegoro \\ $\underline{\text { fanila.pas3ul@gmail.com }}{ }^{1}$
}

Submit, 24-11-2020 Accepted, 24-12-2020 Publish, 25-12-2020

\begin{abstract}
This study is aimed to analyze a morphological process in the marker of benefactive verbs and causative verbs construction of Madurese Language. The theory used in this study was of generative morphology and syntax. The object of this study was Madurese Language. The data collected in Madurese Language was from the native speakers of Madurese. The result of this research was the formation rules of benefactive verbs and causative verbs of Madurese Language by using word and paradigm approach. The results show that there were three kinds of affixation to produce the benefactive verbs. Affixation in the marker of benefactive verb was shown by prefixes $a-m a-$, and $n-$, and suffix $-a g h i$. Affixation in the marker of causative verb was shown by prefixes ma-. Madurese also use intransitive verb and also adjective as the root to construct benefactive verb and causative verb.
\end{abstract}

Keyword: Benefactive Verbs, Causative Verbs, Generative Morphology, Madurese

\section{INTRODUCTION}

The diversity and uniqueness of language in the world is an interesting linguistic phenomenon that can be studied. Word formation is one of interesting research object because every language has diversity in word formation which is called as morphological process.

Madurese language is one of the languages that recently spread through almost all over the Java Island. Most people in Java are able to speak Madurese (Mulyadi, 2007). In Madurese language there are some words or lexemes which become root of words and these words may have new meanings when they are attached to morphemes or affixes. There are many variations of morphemes combination in Madurese language. The morphemes that can be combined is affix of benefactive verbs and causative verbs markers. This affix of benefactive verb is 
attached in two ways: first it is attached directly to the root of noun without any changes and second it is added to the root with a change from the root.

There were several studies related to benefactive and causative verbs as in Azizah, et.al (2020) they found that there are two forms of causative construction in Sasak, morphological and lexical. Morphological causative adding confix N ang/in and affix -in to non-causative base verb, adjective or noun whereas lexical causative uses causative verb mate 'died/killed'. They also found that the formation of causative with intransitive verb is moving $\mathrm{S}$ to $\mathrm{O}$ position while the transitive verbs is performed with type iii; $\mathrm{A}$ and $\mathrm{O}$ become $\mathrm{O}$. Another study came from Sukarini (2013) who found that causative construction of Indonesian language can be seen through two perspective morphosyntax and semantic.

While some studies related to Madurese language, the first study was conducted by Sofyan (2012) based on the meaning of verb, Madurese language consists of reciprocal, reflexive, causative, repetitive and imperative. When it is imperative, stem only can stand alone. The other studies is conducted by Musaffak (2011) from this study it can be concluded that there are thirteen pattern of reduplication in Madurese language.

Unlike previous studies that elaborate in traditional descriptive, the researcher focuses on the morphological processes in the combination of root and the affixes of benefactive verb markers and causative verb markers. Therefore researcher is interested to analyze what process will happen if the affix of benefactive verb and causative verb are constructed.

\section{LITERATURE REVIEW}

\section{Benefactive verb and causative verb in Madurese}

According to Sofyan (2012) causative verb in Madurese language is a verb that state an action "make something happen". For the example in word madalem (to deepen). Benefaktive verb in Madurese is a verb that state an action which is done by someone for someone else. Benefactive verb in Madurese such as melleaghi (buy), and ngala'aghi (take).

\section{Generative Morphology}

Morphology is the study of morphemes and the arrangement of morphemes in forming words (Nida 1949:1). One of theories known by linguist talking about morphology is transformational generative suggested by Chomsky. Principals of generative morphology, according to Chomsky, generally can be described in some explanation.

First, generative morphology is a theory about competence which refers to the knowledge owned by native speaker about his own language and not about performance which refers to the use of language in daily life of the native speaker. 
Generative morphology is based on competence and not performance because linguistic theory is created to find the mental realization that becomes basic of someone's behavior. Second, language is creative and innovative, meaning a speaker can create various and new sentences understand them and analyze the acceptance of those sentences in daily life. Third, generative morphology is a tool to analyze and formulate the rule of forming a sentence, interpreting the sentence, and pronouncing it. Fourth, language is the mirror of one's thought, meaning that language help people to understand others' thought (Ba'dulu \& Herman, 2004).

\section{Morpheme}

When we are writing or speaking, we use words which can be segmented into smaller segment. For example is in speaking which can be segmented into smaller parts, 'speak' and 'ing'. These small parts are what we call "morpheme". Simply, morpheme can be said as the smallest meaningful constituents in a certain linguistic expression. Morpheme itself can be divided into two types: free and bound morpheme. Free morpheme is independent morpheme, meaning that this type of morpheme has clear and concrete meaning without being combined with other morphemes. The examples are book, bag, speak, walk, small, big, well, and right. Bound morpheme is the vice versa of free, meaning that this type of morpheme does not have clear meaning until it is attached to free morphemes. The ones included in this type are in form of affixations such as '-ing', 's', '-es', 'ed', '-ful', and other affixations (Booji, 2005).

Root

When a speaker use words in daily life, he sometimes says or writes words which contain more than one morpheme like in 'unintentionally'. These words can be segmented into smaller part, bound and free morphemes. The segmented free morpheme that cannot be analyzed further into constituent morphemes is what we call root. In word 'unintentionally' we can have 'un-', 'intend', '-ion', 'al', and '-ly'. The free morpheme 'intend' is the root since it cannot be segmented anymore (Booji, 2005).

\section{Prefix, Infix, and Suffix}

As has been stated above, there is morphemes that called affix which will have concrete meaning if they are attached to free morphemes. There are three kinds of affix which each are classified or named based on the position of the attachment. When the affix is attached in the front of the base or root, it is what we call prefix, i.e. imperfect, undone, disagree. When the affix is attached in the middle of the root or base that is infix, i.e. gerigi. Suffix is the affix which is 
attached at the end of the root or base like in readable, activity, and movement (Booji, 2005).

\section{Approaches in Analyzing Morphological Rules}

When a researcher analyzes the morphological process, one of goals is to find the regularity or generalization of the rules which are applied in a certain language. There are three approach which can be conducted to find this generalization, they are "Item and arrangement" which focuses on the arrangement of morphemes in a morph, "Item and process" which focuses on the morphophonemic of the morph, and the last one which is used in this paper is "Word and paradigm" which focuses on how the new lexeme are created in a specific language. The chosen approach is Word and Paradigm approach or also called word based model since it has the ability to analyze the fundamental or significance of the word emphasized and the relationship between complex words by formulating word-schemas that represent the common features of sets of morphologically related words (Haspelmath, 2002).

\section{Syntax}

\section{$X$-bar Theory}

$\mathrm{X}$-bar theory is an element of linguistic theory which attempts to identify syntactic features of individual languages. X-bar theory was first proposed by Noam Chomsky and further developed by Ray Jackendoff. Newson labeled X-bar as a theory of fundamental structure containing of three different rules which resolve the character of all structures in a language. X-bar theory is widely regarded as a substantive theory of phrase structure properties in natural languages.

Specific categories assigned are $\mathrm{N}$ for noun, $\mathrm{V}$ for verb, $\mathrm{A}$ for adjective, $\mathrm{P}$ for preposition or $\mathrm{D}$ for determiner. Thus these rules tell us how phrases in general are structured. The complement always appears closer to the head. The head is the central element of the phrase. The specifier rule, as it has the structural position as specifier. The specifier of the DP is the possessor and this precedes the $\mathrm{D}^{\text {ee }}$ constituted of the determiner and its complement (Newson et al., 2006).

An adjunct is optional, or structurally dispensable, part of a sentence, clause, or phrase that, when removed, will not affect the remainder of the sentence except to discard from it some auxiliary information. An adjunct is not an argument (nor is it a predicative expression), and an argument is not an adjunct.

\section{Constituent Structure}

A constituent is a word or a group of words that functions as a single unit within a hierarchical structure. The analysis of constituent structure is 
associated mainly with phrase structure grammar (Miller, 2002). The constituent structure of sentences is identified by using constituency tests. These tests manipulate some portion of a sentence and based on the result, clues are delivered about the immediate constituent structure of the sentence. According to Miller (2002) there are three sequence of words which forms a phrase, such as, transposition, substitution and ellipsis.

\section{Categories of Constituent Structure}

\section{Lexical Categories}

A lexical category is a linguistic category of words (or more precisely lexical items), which is generally defined by the syntactic or morphological behavior of the lexical item in question. Grady, William, Dobrovolsky, \& Katamba (1997) argue that the four most studied lexical categories are noun $(\mathrm{N})$, verb (V), adjective (A), and preposition (P). A fifth and less studied lexical category consist of adverb (Adv), most of which are derived from adjectives. Those lexical categories are the head of noun phrase (NP), verb phrase (VP), adjective phrase (AP), prepositional phrase (PP), and adverbial phrase (AdvP).

\section{Noun Phrase}

A noun phrase is a phrase which has a noun (or indefinite pronoun) as its head word, or which performs the same grammatical function as such a phrase. Noun phrases often function as verb subjects and objects, as predicative expressions, and as the complements of prepositions.

\section{Verb Phrase}

Verb phrase is a phrase that is headed by a verb. A verb phrase may be constructed from a single verb. A verb phrase or VP is a syntactic unit composed of at least one verb and the dependents of that verb - objects, complements and other modifiers, but not include the subject. In syntax, there is a transitive verb that is a verb that requires one or more objects and intransitive verbs that do not have objects. VPs can be constructed from a single verb, however the verb phrase will consist of various combinations of the main verb and any auxiliary verbs, plus optional specifiers, complements, and adjuncts.

\section{Adjective Phrase}

An adjective is a phrase with an adjective as its head. This adjective may be accompanied by modifiers, determiners, and/or qualifiers. Adjective phrases may be attributive (appearing before the noun) or predicative, but not all adjectives can be used in both positions. An adjective phrase consists of an adjective which may be preceded and/or followed by other words. 


\section{Adverbial Phrase}

An adverbial phrase is a word group with an adverb as its head. This adverb may be accompanied by modifiers or qualifiers. An adverb phrase can modify a verb, an adjective, or another adverb.

\section{Prepositional Phrase}

Prepositional phrases have a preposition as the central element of the phrase, which is the head of the phrase. The remaining part of the phrase, usually a noun (phrase) or pronoun

\section{Functional Categories}

Functional Categories are parts of speech that provide inflectional or grammatical information for phrases and clauses, including determiner (D) and inflection (I) which each of them stands as a head of determiner phrase (DP) and inflectional phrase (IP).

\section{Determiner Phrase}

A determiner phrase (DP) is a functional category, a phrase headed by a determiner. The noun phrase is strictly speaking a determiner phrase, and NP designates a constituent of the noun phrase, taken to be the complement of the determiner.

\section{Inflectional Phrase}

An inflectional phrase is a functional phrase which has inflection properties (such as tense and agreement). An Inflectional phrase is essentially the same as a sentence, but reflects an analysis whereby a sentence can be treated as having a head, complement and specifier, like other kinds of phrase.

\section{RESEARCH METHOD}

This research was qualitative descriptive research. In this research, the researcher collected the data by listing nouns and the morphemes of benefactive verb and causative verb in Madurese language. The researcher collected the data from three of native speakers from Madura, then wrote the list of the verbs and the affixes which are attached to the verb and confirmed the list to the other native speakers of Madurese language in Madura. The samples were then classified based on the suffixes attached to the root and additional morphemes until researcher got the groups of words from which there could be taken generalization of attachment rules. After putting those verbs in groups, researcher analyzed the variations of attachment and formulated general rules based on the similarities in the attachment of the suffixes to the root. To analyze the morphological process, 
researcher chose generative morphology approach to analyze the data since it is appropriate for complex word formations, therefore he could see the processes of the attachments in detail. Finally, from the description researcher got conclusion about how the rules to attach the suffixes and morphemes of benefactive verb and causative verb marker into the root.

\section{FINDINGS}

\section{Benefactive Verb}

We can see from the data, when Madurese speakers formulate the benefactive verbs, they will add prefixes and suffix to the verb, adjective, and noun. There are three affixes showing the benefactive verb in Madurese. They are A-aghi, Ma-aghi and $N$-aghi. Below are the analyses of the data:

Table 1. Rule 1

\begin{tabular}{lll}
\hline Root & Meaning & Benefaktive Verb \\
\hline Kala? & Take & NgalaPaghi \\
Buweng & Throw & Muwengaghi \\
Tanem & Plant & Nanemaghi \\
Ajer & Teach & Ngajeraghi \\
Deteng & Come & Netengaghi \\
Sempen & Save & Nyempenaghi \\
Pasang & Set & Masangaghi \\
Obe & Change & Ngobeaghi \\
Careta & Told & NyretaPaghi \\
Massak & Cook & Massa?aghi \\
\hline
\end{tabular}

From to the data shown in the table above, researcher can conclude that to form a benefactive, Madurese add prefix $N$ - and suffix -aghi. But there are some assimilation process that occur in the data. From the environments classification, researcher can formulate three rules for the assimilation processes in this language using distinctive features which enables to write a complete description of the phonological processes in this language. The rule is: / $/ \rightarrow / \mathrm{n} \mathrm{X}$ aghi/ (If root initialize with consonant $\mathrm{g}$ and $\mathrm{j}$, add prefix $n$ - and suffix -aghi to the root). Here, sound $/ \mathrm{n} /$ will transform into sounds [m], [n], or [n] based on the environment as describe below:

\section{Formula 1}

In this first rule there is one assimilation process where the phoneme $/ \mathrm{n} /$ will transform into $[\mathrm{m}]$ when it meets consonants $[\mathrm{b}],[\mathrm{m}]$ and $[\mathrm{p}]$. The example of this assimilation process is as below: 
Table 2. Formula 1

\begin{tabular}{llll}
\hline /buweng/ & {$[$ muwengaghi $]$} & {$[\mathrm{m}-]$} & Throw \\
\hline$/$ massa?/ & {$[$ massaPaghi $]$} & {$[\mathrm{m}-]$} & Cook \\
\hline /pasang/ & {$[$ masangaghi $]$} & {$[\mathrm{m}-]$} & Set \\
\hline
\end{tabular}

Formula 2

In the second rule the assimilation process is that where the phoneme $/ \mathrm{n} /$ will transform into [y] when it meets consonants [k], [a], or vowel [o].

Table 3. Formula 2

\begin{tabular}{llll}
\hline$/$ kalaP/ & {$[$ yalaPaghi] } & {$[\mathrm{y}-]$} & Take \\
\hline /ajer/ & {$[$ yajeraghi] } & {$[\mathrm{y}-]$} & Teach \\
\hline /obe/ & {$[$ yobeaghi] } & {$[\mathrm{y}-]$} & Change \\
\hline
\end{tabular}

\section{Formula 3}

As in the first and second rule, in the third rule there is also assimilation process. The assimilation process is that where the phoneme $/ \mathrm{n} /$ will transform into [n] when it meets consonant [s] and [c] like in example below:

Table 4. Formula 3

\begin{tabular}{llll}
\hline$/$ sempen/ & {$[$ nempenaghi $]$} & {$[\mathrm{n}-]$} & Save \\
\hline$/$ careta/ & {$[$ naretaPaghi $]$} & {$[\mathrm{n}-]$} & Tell \\
\hline
\end{tabular}

\section{Rule 2}

Table 5 Rule 2

\begin{tabular}{lll}
\hline Root & Meaning & Benefaktive verb \\
\hline Bali & Return & mabali?aghi \\
Ongge? & Bring up & maongge?aghi \\
\hline
\end{tabular}

According to the data shown in the table above, to construct benefactive verb, the rule is by adding prefix ma-and suffix -aghi directly to the root. 
Rule 3

Table 6 Rule 3

\begin{tabular}{lll}
\hline Root & Meaning & Benefaktive verb \\
\hline Gebey & Make & Agebeyyaghi \\
Jhuwal & Sell & Ajhuwwallaghi \\
Tana? & Cook & Atana?aghi \\
\hline
\end{tabular}

According to the data shown in the table above, researcher can conclude that to construct benefactive verb, the rule is by adding prefix $a$ - and suffix -aghi directly to the root. The rule is: /X g,j / $\rightarrow / \mathrm{a} X$ aghi/ (If root initialize with consonant $\mathrm{g}$ and $\mathrm{j}$, add prefix $a$ - and suffix $-a g h i$ to the root)

\section{Causative Verb}

Table 7 Causative Verb

\begin{tabular}{lll}
\hline \multicolumn{1}{c}{ Root } & \multicolumn{1}{c}{ Meaning } & \multicolumn{1}{c}{ Causative verb } \\
\hline Ghebey & Membuatkan & Maghebey \\
\hline Dalem & Mendalamkan & Madalem \\
\hline Jhau & Menjauhkan & Majhau \\
\hline Jheghe & Membangunkan & Majheghe \\
\hline Bhingong & Membingungkan & Mabhingong \\
\hline Bhagus & Menjadikan bagus & Mabhagus \\
\hline
\end{tabular}

According to the data shown above, the rule to construct causative verb is by adding prefix ma- directly to the stem and there is no suffix. Causative verb in Madurese language generally is marked by prefix ma- in the form of adjective.

\section{DISCUSSION}

From the description of the analysis of the data above, it is seen that there is no exact rule what prefix to use between $N-, A$-, and $M a$ - by the root with certain characteristic since we can see from data in the rule 1 for muwengaghi and from data in the rule 2 for maballiaghi, even though both root initialize with sound / $\mathrm{b} /$ for buweng and balli, but they use different prefix, that are prefix $\mathrm{N}$-, and $m a-$. The other prove is that the root initialize by sound /o/ also can have both prefix $N$ - and ma- like in ngobeaghi from root obe and maonggeaghi from root ongge. 


\section{Constituency Analysis}

Emmak ngebeyaghi roteh brownis gebey engko' (Mommy made brownies cake for me)

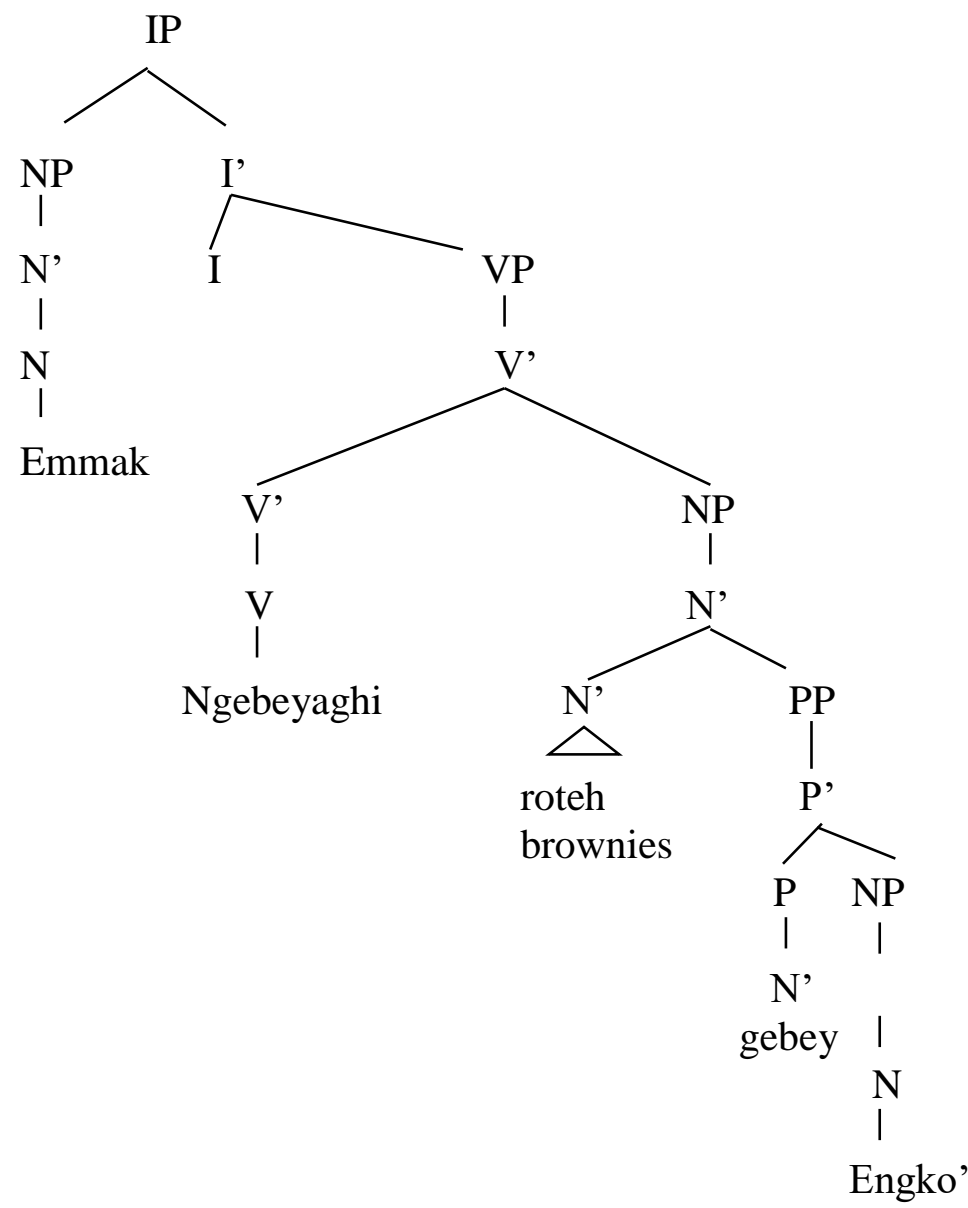

The data shows that IP is the head of the sentence where a VP is the complement of the sentence, and a noun phrase (NP), which is structurally the specifier of the sentence, and serves as the subject of the sentence above. We have seen that the sentences above, IP is the head. Furthermore, the sentence allow 3 arguments and most of the data for benefactive verb acquire intransitive verb gebey (make).

\section{CONCLUSION}

Based on morphological analysis on the benefactive verb construction in Madurese language, it can be concluded that there is no exact rule for certain root with the benefactive know that some roots even though have the similar environtment but they have different affix for benefactive marker. Furthermore, from the constituency analysis, the use of benefactive verb in sentences shows that benefactive verb allow 3 arguments and for constructing benefactive verb, 
Madurese use intransitive verb and also adjective as the root. The rule to construct causative verb is by adding prefix ma- directly to the stem and there is no suffix. Causative verb in Madurese language generally is marked by prefix ma- in the form of adjective.

\section{REFERENCES}

Azizah, N., Artawa, K., Indrawati, N. L. K. M., \& Satyawati, M. S. (2020). Causative in Sasak: A Mechanism of Valency Increase. Journal of Language Teaching and Research, 11(3), 491. https://doi.org/10.17507/jltr.1103.19

Ba'dulu, A. M., \& Herman, H. (2004). Morfosintaksis. Jakarta: PT. Rineka Cipta.

Booji, B. (2005). The Grammar of Words. London: Oxford University Press.

Grady, O., William, D., Dobrovolsky, M., \& Katamba, F. (1997). Contemporary Linguistics: An Introduction. United Kingdom: Addison Wesley Longman.

Haspelmath, M. (2002). Understanding Morphology. London: Oxford University Press.

Miller, J. (2002). An Introduction to English Syntac. Edinburgh: Edinburgh University Press.

Mulyadi, M. (2007). Potensi Pergeseran dalam Bahasa Madura. Okara Jurnal Bahasa dan Sastra, 3(2).

Musaffak, M. (2011). Reduplikasi Kata dalam Bahasa Madura. Jurnal Artikulasi, 12(2), 798-804.

Newson, M., Hordos, M., Pop, D., Szecsenyi, K., Toth, G., \& Vincze, V. (2006). Basic English Syntax with Exercises. Budapest: Bolcsesz Konzorcium HEFOP Iroda.

Sofyan, A. (2012). Perilaku dan Makna Verba dalam Bahasa Madura. Humaniora, 24(3), 333-344.

Sukarini, N. W. (2013). Causative Construction in Indonesian Language. Lingual: Journal of Language and Culture, 1, 51-63. 